\title{
Prevalence of intestinal parasites (Entamoeba species and giardia lamblia) in duhok and erbil cities, Northern Iraq
}

\begin{abstract}
Background: Intestinal protozoan parasites conceder as important parasite that infect human, and there are high infection rate in human in word. This epidemiological study carried out in Hivi pediatric hospital and central lab. In Duhok and Erbil cities/northern Iraq. The sample collection was from the June to the August 2016 (3 months) and about 77 stools samples were collected from diarrheal patient. 47 samples in Duhok city and 35 samples in Erbil city.
\end{abstract}

Methods: By microscopic fecal examination all stools samples were examined by direct wet smear and iodine staining.

Results: Entamoeba species and Giardia lamblia were found in stools sample of diarrheal patients. Entamoeba species parasite was higher than Giardia lamblia in both Duhok and Erbil cities. In this study the rate of Enamoeba species and Giardia lamblia in Duhok city was 11(26.1\%)and 4(9.5\%) respectively, and in Erbil city the rate of infection by Enamoeba species and Giardia lamblia was $8(22.8 \%)$ and 2(5.7\%) respectively.

Conclusion: The present epidemiological study show that the prevalence of intestinal parasites special Entamoeba species parasite in Duhok and Erbil cities are still high and it's require good strategies and plans to prevent distribution of these parasites.

Keywords: intestinal parasites, entamoeba specie, giardia lamblia, prevalence
Volume 4 Issue 6 - 2017

\author{
Hasan Yilmaz,' Arshad M Abdullah² \\ 'Faculty of Medicine, Yuzuncu Yil University, Turkey \\ ${ }^{2}$ College of Pharmacy, University of Duhok, Iraq
}

Correspondence: Arshad M Abdullah, College of Pharmacy, University of Duhok, Iraq, Email arshadzanko@yahoo.com

Received: February 05, 2017| Published: May 09, 2017

\section{Introduction}

There is high prevalence of intestinal parasite throughout the world; it's more than three billion people which are infected with these parasites. ${ }^{1}$ There are direct relation between infection with intestinal parasites and socioeconomic status. In area with low hygienic condition there are more infection with intestinal parasite and many studies reports these parasites in low socioeconomic status area. ${ }^{2-6}$ For control of these parasites it's require the good planning and good studies for determination of epidemiological researches and data about different area. There are many risk factors that directly effect on people to infect parasite in many area, for prevent process there are special methods and plans that it should be used. The aim of this study about intestinal parasites is that to determine and know the rate of infection by parasite in Duhok and Erbil cities/ North Iraq, to obtain and find the infection data and percentage to use in future studies as epidemiological data.

\section{Materials and methods}

\section{Sample collection}

The sample collection was in Duhok Hivi pediatric hospital and Erbil central Laboratory from the June to the August 2016 (3 months). About 77 stools samples were collected from diarrheal patient and the stool samples were collected in a special bottle and transported to laboratory in College of Science/ University of Duhok and were stored in deep freezer.

\section{Microscopic examination of stools samples}

In laboratory all samples were processed by direct wet smear and iodine staining and examined via microscopy for the presence of Entamoeba species and the results were write in Table 1.

\section{Results}

By microscopic fecal examination 2 intestinal parasite were found in stools sample of diarrheal patients, which the more prevalent parasite was Entamoeba species parasite and the second was Giardia lamblia. In these diarrheal patients stools only protozoan parasite were found by microscopic examination. Prevalence of protozoan intestinal parasites in Duhok and Erbil city are shown in Table 1.

\section{Discussion}

One of the important health problem in human are parasitic infection, the prevalence rates are different according to life level, behavior style and hygienic level. In this study were shown $26.1 \%$ and $22.8 \%$ of infection in patients with Entamoeba species, in both Duhok and Erbil cities respectively. In Duhok city was shown 11 infected people from 42 examined, and in Erbil city was shown 8 infected people from 35 examined patients. These data shown that the prevalence percentage in Duhok city is higher than Erbil city in Entamoeba species Parasite. In Table 1, we can see the prevalence of Giardia lamblia in both Duhok and Erbil cities, which the rates of infection were shown $9.5 \%$ in Duhok city and $5.7 \%$ in Erbil city. According to this study we can show that the Giardia lamblia infection in Duhok city was higher than Erbil city, but because of low number of collected sample in Erbil than Duhok, this different is not more significant.

Also in this study we can see the infection with both Entamoeba species and Giardia lamblia parasite in one infected person in Duhok 
city. When we compare this study with other studies in Erbil and Sulaimaniye cities of Iraq, we can see high differences in results percentage, for example amoebic infection in Erbil city/ Iraq was reported about $19 \%$ by. ${ }^{7,8}$ Also the prevalence of amoebic dysentery among children in Pediatric Hospital of Sulaimaniye- Iraq was (39\%). But Hussein, 2010 reported $10.15 \%$ of infection by Entamoeba species in epidemiological study in Duhok city, these results are similar with our finding in this study approximately. In Iraq country several studies reports the prevalence of intestinal parasite in different cities, special protozoan parasites. ${ }^{5}$

When we compare this study with other studies we can see the different in parasite species percentage in different area. ${ }^{4}$ According to, ${ }^{9}$ in Turkey, which obtain different infection rate with Entamoeba histolytica, they found that the rate of infection was $11.6 \%$ in the immigrant group people (IG) and $5.9 \%$ in the resident group people (RG), these finding are similar to our finding in Entamoeba parasite approximately. But. ${ }^{4}$ in Iran, reported high prevalence of Giardia lamblia parasite in their study, when we compare with this study data, we can see different data in Giardia lamblia parasite. ${ }^{4}$

\section{Conflicts of interest}

There is no conflict of interest.

\section{Acknowledgements}

None.

\section{Funding}

None.

\section{References}

1. Ali SA, Mohammed LO. Prevalence of intestinal parasite among children in Sulaimani city. J Duhok Univ. 2010;13(1):94-98.

2. Balcioglu IC, Kurt O, Limoncu ME, et al. Rural life, lower socioeconomic status and parasitic infections. Parasitol Inter. 2007;56(2):129-133.

3. Corrales LF, Izurieta R, Moe CL. Association between intestinal parasitic infections and type of sanitation system in rural El Salvador. Trop Med Int Health. 2006;11(12):1821-1831.

4. EB Kia, M Hosseini, MR Nilforoushan, AR, et al. Study of Intestinal Protozoan Parasites in Rural Inhabitants of Mazandaran Province, Northern Iran. Iranian J Parasitol.2008;3(1):21-25.

5. Hussein JN. Prevalence of intestinal parasites among children in various localities of Duhok province. University of duhok. 2010.

6. Markell EK. Examinations of stool specimens. In: Markell EK \& Voge M(Eds.) Medical Parasitology. Saunders ( $9^{\text {th }}$ edn), Missouri, USA. 2006:480.

7. Molan AL, Farage AM. Prevalency of intestinal parasite in school children of arbil, north of Iraq. Med J. 1989;10:107-110.

8. Nematian J, Nematian E, Gholamrezanezhad A, et al. Prevalence of intestinal parasitic infections and their relation with socioeconomic factors and hygienic habits in Tehran primary school students. Acta Trop. 2004;92(3):179-186.

9. Yilmaz H, Akman N, Göz Y. Distribution of intestinal parasites in two societies with different socio-economic status in Van. Eastern Journal of Medicine. 1999;4(1):16-19. 